
\title{
CIÊNCIANATURA
}

\section{Variabilidade termo-higrométrica em diferentes usos da terra no entorno do Reservatório Ernestina, Ernestina/RS, em situação de inverno}

Thermo-hygrometric variability in different land uses around the Ernestina Reservoir,

Ernestina/RS, in winter conditions

Denise Cristina Borges ${ }^{1}$, Cássio Arthur Wollmann ${ }^{2}$ e Jakeline Baratto ${ }^{3}$

${ }^{1}$ Licenciada em Biologia pela UNISINOS, Mestre em Geografia, PPGGEO, Universidade Federal de Santa Maria, Santa Maria, Brasil

deniseborges_cb@yahoo.com.br

${ }^{2}$ Professor Orientador PPGGEO, Departamento de Geociências, Universidade Federal de Santa Maria, Santa Maria, Brasil cassio_geo@yahoo.com.br

${ }^{3}$ Geógrafa e Mestre em Geografia pela UFSM, Doutoranda PPGGEO, Universidade Federal de Santa Maria, Santa Maria, Brasil jekeline.jake@hotmail.com

\section{Resumo}

A presente pesquisa tem como objetivo geral analisar a variabilidade termo-higrométrica em três distintos usos da terra próximos ao Reservatório Ernestina, no municipio de Ernestina/RS, durante o mês de julho de 2015, em escala diária e horária, com a proposição de um painel têmporo-espacial de análise dos dados. Fez-se fundamentação teórica, e posteriormente, foram coletados os dados dos elementos climáticos de temperatura e umidade relativa do ar em campo, com base na metodologia de Wollmann e Simioni (2013). Foram instalados três mini-abrigos meteorológicos em cada uma das três áreas de estudo selecionadas para a coleta de umidade e temperatura, conforme metodologia de Hoppe (2015). Além das análises estatísticas, foi aplicada a técnica de representação gráfica por painéis Têmporo-Espaciais, que conforme Zavattini e Boin (2013). Os principais resultados encontrados foram que o fragmento florestal apresentou uma menor variação termo-higrométrica em comparação com a lavoura e o banhado, sofrendo menor interferência dos elementos do clima sobre a sua área, tanto de noite como durante o dia. A lavoura foi a que se apresentou com uma variação maior na temperatura e umidade, com temperaturas mais elevadas e umidade mais baixa em comparação com o banhado e o fragmento florestal.

Palavras-chave: Variabilidade termo-higrométrica, uso da terra, Ernestina/RS

\section{Abstract}

This research concerns in to analyze the thermo-hygrometric variability in three different land uses near the Ernestina Reservoir, in the city of Ernestina/RS, during the month of July 2015, in daily and hourly scale, with the proposition of a spatial-temporal dashboard of data analysis. Theoretical basis was used, and data on the climatic elements of temperature and relative air humidity in the field were collected, based on the methodology of Wollmann and Simioni (2013). Three meteorological minishelters were installed in each of the three study areas selected for the collection of humidity and temperature, according to Hoppe's methodology (2015). Besides the statistical analyzes, the technique of graphical representation by Temporal-Space panels was applied, according to Zavattini and Boin (2013). The main results were that the forest fragment presented a lower thermo-hygrometric variation in comparison to the crop and the plains, suffering less interference of the elements of the climate over its area, both at night and during the day. The crop was presented with a higher variation in temperature and humidity, with higher temperatures and lower humidity in comparison with the plots and the forest fragment.

Keywords: Thermo-hygrometric variability, land uses, Ernestina/RS 


\section{Introdução}

O uso da terra e a dinâmica dos ecossistemas florestais são capazes de interferir na qualidade da água e no regime de vazões dos cursos de água. Há uma atividade complexa de fluxos de entrada, armazenamento e saída de nutrientes nestes ambientes. Desse modo, investigações a respeito da dinâmica do clima são de suma importância para compreensão da forma como os processos naturais interferem no meio ambiente.

A Climatologia trabalha com escalas espaciais para a melhor compressão nos estudos, definidas em: macroclimática, mesoclimática e microclimática. A escala macroclimática é a que possui maior abrangência, analisando desde o clima global, zonal, regional, e áreas de grande amplitude como oceanos, continentes e grandes países. Já a escala mesoclimática em uma ordem intermediária da macroclimática e microclimática se detêm às observações do clima em cidades, regiões metropolitanas, os desertos, grandes florestas, etc. E a microclimatologia, a escala mais inferior, se atém ao estudo das áreas com extensões pequenas, geralmente de centímetros a algumas centenas de metros quadrados (MENDONÇA; DANI-OLIVEIRA, op. cit.).

Segundo Lima (2009) as pesquisas desenvolvidas na área de Climatologia têm em sua maioria, enfocado a escala macroclimática. Todavia, provocada pela necessidade do desenvolvimento de estudos ambientais tem-se exigido o desenvolvimento de análises em escalas inferiores do clima, notadamente microclimáticos. Para o qual a natureza desse tipo de investigação se justifica pela necessidade de se entender em escalas inferiores como se processa a relação entre os componentes do meio físico e a estrutura da vegetação.

Atualmente vários estudos em microclima vêm sendo desenvolvidos em ambientes urbanos direcionados à ecologia $\mathrm{e}$ agricultura, até relacionados com a influência de lagos artificiais na instalação de centrais hidrelétricas (LIMA, 2009). Uma vez que se depara com a necessidade de uma maior compreensão a respeito da dinâmica dos seres com a dinâmica do meio abiótico, as relações existentes entre a atmosfera, a interferência dos fatores geográficos verificados nos ambientes e as alterações provocadas pelo homem no seu uso do espaço geográfico.

Quando se trabalha em uma escala espacial mais próxima da escala de vida do homem e dos seres vivos, como os microclimas, torna-se possível investigar qual a influência climática exercida pelo meio aos seres vivos e vice-versa. A sobrevivência, evolução e distribuição dos seres vivos estão atreladas a esta inter-relação físico-fisiológica ao longo do tempo cronológico de curta e longa duração.

As condições de variação no meio ambiente quando pensada em estudos em escalas mesoclimáticas e macroclimáticas não vão apresentar acentuadas diferenças, visto a natureza do tipo de pesquisa que concebem. Porém, a presença de variações nas áreas quando observadas pela perspectiva teórica dos estudos microclimáticos, evidenciam elementos de apreciação, pois a análise microclimática considera a relação existente entre os componentes do meio físico em escalas inferiores.

Neste intuito a presente pesquisa tem como objetivo geral analisar a variabilidade termo-higrométrica em três distintos usos da terra próximos ao Reservatório Ernestina, no município de Ernestina/RS, no período de inverno, especificamente, durante o mês de julho de 2015, em escala diária e horária, com a proposição de um painel têmporo-espacial de análise dos dados ${ }^{1}$.

\section{2 Área de estudo}

A área de estudo está inserida em uma propriedade particular com aproximadamente 140 ha, localizada na zona rural do município de Ernestina. Estando ao nordeste da área urbana do município, com latitude de $28^{\circ} 29^{\prime}$ '56”sul e longitude de 52 $34^{\circ}$ ' $24^{\prime}$ ” oeste, a uma altitude média de 493 metros. Na Figura 1 é possível observar especificamente a disposição das áreas onde foram realizadas esta pesquisa, definidas como Área 1, Área 2 e Área 3, juntamente com a demarcação do raio de abrangência (100m) dos estudos em cada área.

A área situa-se no Bioma Mata Atlântica em meio a duas formações vegetais, identificadas como "Campos" e "Floresta Ombrófila Mista”. Conforme estudos climáticos para o estado do Rio Grande do Sul de Rossato (2011), o município de Ernestina encontra-se inserido como clima subtropical III, no qual, a autora define como úmido com variação longitudinal de temperaturas médias, sofrendo menor influência dos sistemas polares e maior dos sistemas tropicais associados aos fatores climáticos, de relevo (escarpa e vales da borda do Planalto Basáltico), da continentalidade, da maritimidade e das áreas urbanizadas. Com a temperatura média anual entre $17^{\circ} \mathrm{C}$ e $20^{\circ} \mathrm{C}$, a temperatura média do mês mais frio entre $11^{\circ} \mathrm{C}$ e $14^{\circ} \mathrm{C}$, a temperatura do mês mais quente entre $23^{\circ} \mathrm{C}$ e $26^{\circ} \mathrm{C}$ e as chuvas anuais com variação entre 1700 e 1800 mm, ocorrendo de 100-120 dias de chuvas e normalmente no mês de 9 a 12 dias (ROSSATO, 2011).

Em um estudo realizado pela Companhia Estadual de Energia Elétrica - Geração e Transmissão, em 2008, no entorno dos 100 metros próximos do Reservatório Ernestina, na Bacia Hidrográfica do Alto Jacuí, é caracterizado pela presença de mais de 60\% em uso agrícola, 34\% em mata nativa, 2\% de silvicultura e 3\% residencial. Em estudos de Ziani e Prina (2015) de mapeamento do uso da terra no entorno do Reservatório Ernestina, comparando imagens do sensor Landsat-TM 5, de 1988 e 2011, apontam a diminuição nestas áreas de floresta, de $27,8 \%$ para $14,4 \%$.

O presente artigo é fruto de uma parte da dissertação de mestrado desenvolvida junto ao Laboratório de Climatologia Ambiental e Subtropical (LaCAS/UFSM), sob orientação do professor Dr. Cássio Arthur Wollmann, no período de 2015 a 2017. 


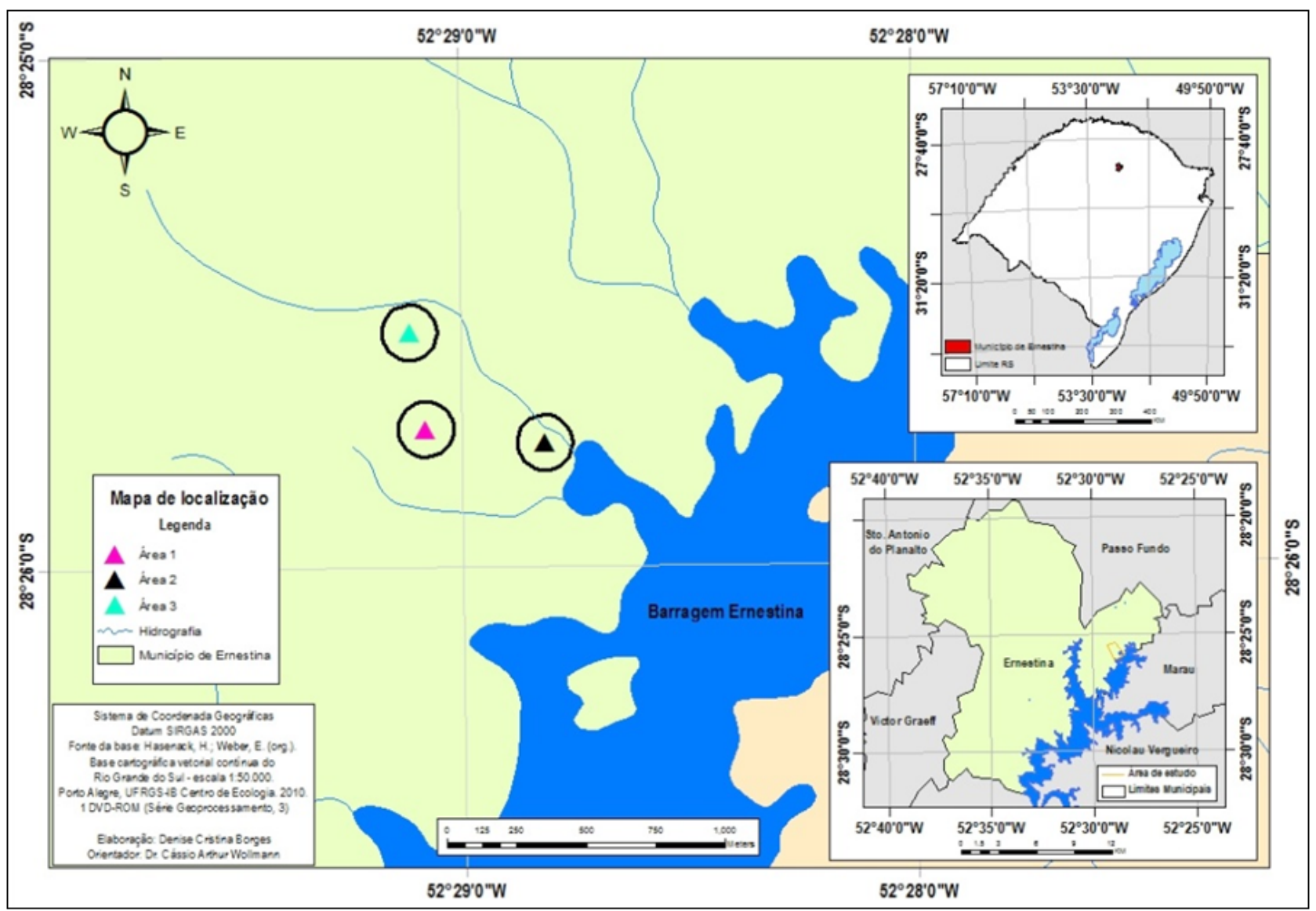

Figura 1 - Localização da área de estudo.

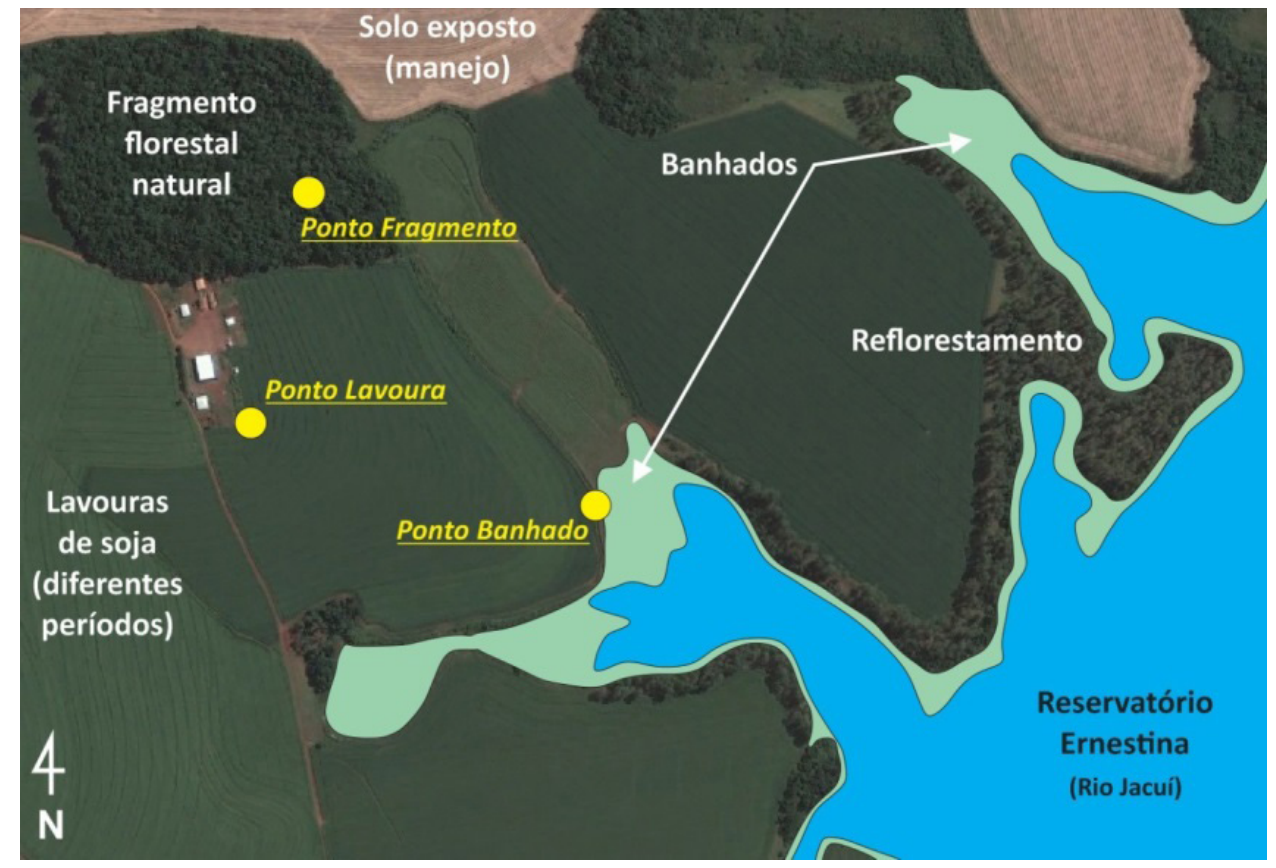

Figura 2 - Uso da terra nas áreas de estudo. 
Justamente a presença das áreas úmidas, associadas aos fragmentos de vegetação nativa e uso da terra para finalidade agropastoril com sazonalidades definidas motivaram a escolha desta área para a realização do estudo. O que pode ser observado através da Figura 2, no qual se definiram os três pontos para a realização do estudo.

A primeira área definida como Área 1, ocorre a incidência da cultura da soja durante o ano ocupando uma extensão de 15 ha de área. O cultivo dessa cultura agrícola é desenvolvido em dois momentos: entre os meses de outubro a fevereiro ocorre o plantio e desenvolvimento da planta. Nos meses de março até maio ocorre a etapa de colheita. No segundo momento da área, entre os meses de junho até setembro, o solo fica mais exposto, dando crescimento espontâneo de algumas gramíneas na área.

A segunda área identificada como Área 2, apresenta uma ocupação do tipo banhado, em uma extensão de aproximadamente 12 ha, sendo caracterizada pela presença de lâmina de água por alguns meses durante do ano, com presença de plantas aquáticas e vegetação arbustiva. Devido às feições de área úmida o solo se apresenta mais saturados e com a presença de fauna e flora típicas. Uma vez que não foi realizado um teste de solo da área para verificar se a composição corresponde com as características hidromórficas de textura argilosa a franco-argilosa, associado com a presença de turfas (LEPSCH, 2002), para fins do desenvolvimento e categorização das áreas identificadas na propriedade, optou-se por empregar a expressão banhado segundo as características visuais identificadas na área.

Das espécies da flora observadas, foram identificadas na área algumas macrófitas, junto aos pontos mais alagados, além da presença de algumas espécies de porte arbóreo/arbustivo/subarbustivo: corticeira-do-banhado (Erythrinacristagalli), aroeiravermelha (Schinusterebinthifolius), maricá (Mimosa bimucronata) fumo-bravo (Solanummauritianum), vassoura (Baccharisdracunculifolia) carqueja (Baccharissp.).

Já a terceira área identificada como Área 3, está caracterizada por um fragmento florestal, apresentando vegetação de porte mais arbóreo/arbustivo, encontrando-se em um estágio médio/ avançado de regeneração da Mata Atlântica, com a vegetação em média estando com o DAP ${ }^{2}$ acima de 15 centímetros. Com abundante presença de serrapilheiracobrindo o solo e cobertura arbórea mais fechada percorrendo uma extensão de 12 hectares.

$\mathrm{Na}$ área foi identificada uma composição florística de matas de araucárias (Araucariaangustifólia) associadas a forte presença de lauráceas, como as canelas (Ocoteaodorífera) e (Ocoteapulchella). Com formação de sub-bosques apresentando incidências de espécies pertencentes à família Anacardiaceae, Myrtaceae, Sapindaceae, Primulaceae, Meliaceae, entre outras.

\section{Materiais e Procedimentos Metodológicos}

O delineamento do estudo foi do tipo quali-quantitativo e abrangeu as técnicas de pesquisa de campo e aplicação de estatísticas descritiva para a melhor compreensão da atuação dos fenômenos climáticos. Primeiramente foi realizada a revisão de fontes teóricas que pudessem orientar a efetivação do trabalho, posteriormente pesquisa a campo para a identificação, caracterização das áreas e coletas dos dados meteorologia. Conforme apresentado na Tabela 1, a propriedade foi categorizada em três áreas conforme suas características predominantes visualmente.

Tabela 1 Categorização da área de estudo segundo o tipo de uso da terra.

\begin{tabular}{c|c}
\hline Área & Categoria \\
\hline Área 01 & Cultivo agrícola \\
\hline Área 02 & Banhado \\
\hline Área 03 & Fragmento Florestal \\
\hline
\end{tabular}

Fonte: A autora, 2016

Foram coletados os dados dos elementos climáticos de: temperatura e umidade relativa do ar em campo, com base na metodologia de Wollmann e Simioni (2013), a partir das orientações da Organização Mundial Meteorológica (OMM, 1992), na qual, os autores salientam que as medições de pequena escala em climatologia são representativas do entorno encontrado dentro de um raio de 100 metros, a partir do ponto de coleta. No caso, a medição refletiria o uso da terra de uma área com no máximo 7.850 metros quadrados de área.

Para o desenvolvimento da coleta de dados foi instalado um mini-abrigo meteorológico em cada uma das três áreas de estudo, 
com equipamento específico de forma a obter-se uma análise dos atributos climáticos de umidade e temperatura. Conforme descreve Ribeiro (1993), o tipo de registro necessário para o estudo do microclima deve ser obtido por meio de aparelhos de alta sensibilidade e precisão, pois devem ser pesquisadas variações em tempo medido em minutos, ou mesmo em segundos.

Assim, para a medição de temperatura e umidade relativa do ar foi utilizado um Datalogger de Temperatura e Umidade, da marca Instrutherm HT500 (Figura 3), pertencente ao Laboratório de Climatologia Ambiental e Subtropical, do Departamento de Geociências da UFSM. Além de instalados os mini abrigos, foram configurados para medição em intervalos de hora em hora, totalizando 24 medições ao longo de cada dia no período de 31 dias.

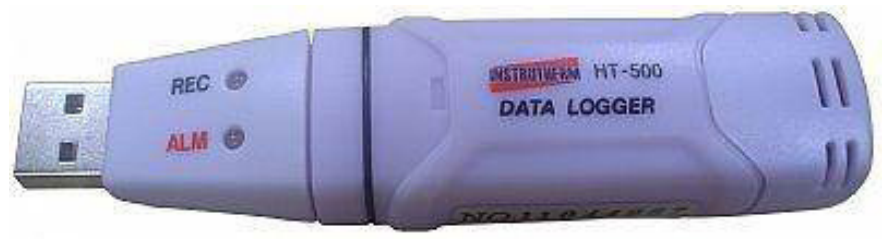

Figura 3 - Datalogger HT-500 Instrutherm Equipamento utilizado para obtenção dos dados de temperatura e umidade relativa do ar

Fonte: Wollmann; Simioni, 2013

Foi realizado um trabalho de campo prévio em março de 2015, para solicitar autorização ao proprietário da área para a realização da pesquisa. Depois de concedida a autorização, foi explicada como seria feita a montagem e desmonte dos equipamentos. E no final do mês de junho foram instalados os Dataloggers já calibrados conforme a indicação de Hoppe, et. al. (2015), em cada um dos três mini-abrigos nas áreas (Figura 4).

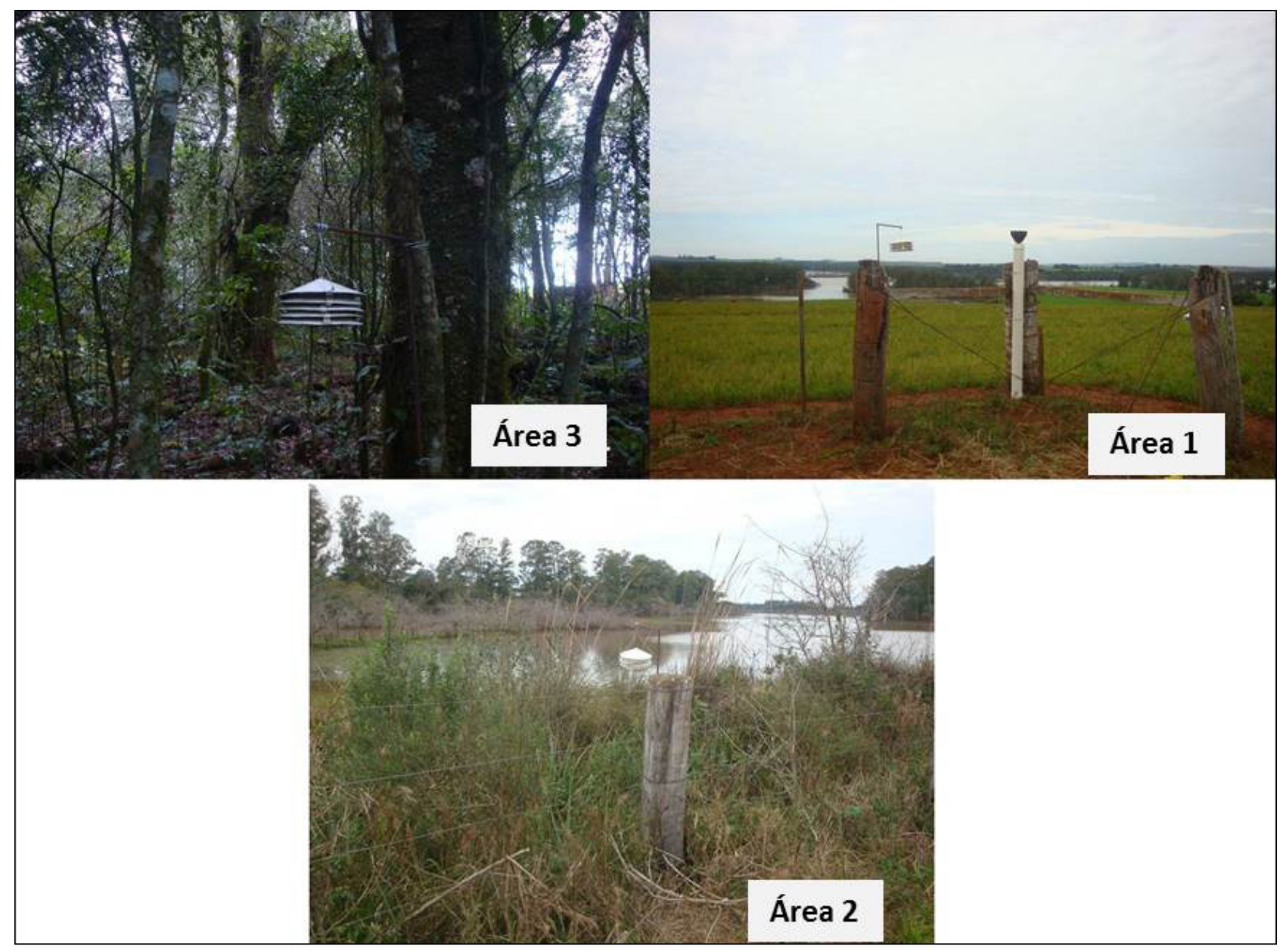

Figura 4 - Instalação dos mini-abrigos na área de estudo Fonte: A autora (2015) 
A programação do Datalogger foi ajustada para que o registro dos dados de temperatura e umidade relativa do ar ocorresse num intervalo de tempo horário (escala temporal horária) no mês de coleta durante a instalação. Fez-se descarte dos dados relativos aos dias anteriores e posteriores ao da instalação e desmonte dos equipamentos, que não fossem referentes ao mês de julho. O procedimento de tratamento dos dados coletados foi orientado no sentido de compreender-se a interação existente nas três áreas com os atributos climáticos de umidade e temperatura. Assim, a interpretação dos dados foi realizada através da aplicação da estatística descritiva onde foram verificadas a tendência central (média aritmética) e a variabilidade (desvio padrão e gráfico de dispersão) dos dados.

Além das análises estatísticas foi aplicada a técnica de representação gráfica por painéis Têmporo-Espaciais, que conforme Zavattini e Boin (2013) é uma técnica baseada na estrutura cartesiana com seus eixos ortogonais x e y para apresentação da sucessão dos estados atmosféricos sobre um determinado lugar.

Para a elaboração destes painéis apresentados na pesquisa foram utilizados às informações coletadas nos mini-abrigos durante o mês de julho de 2015, representativos do inverno. A planilha foi elaborada no programa Surfer ${ }^{\circledR}$, versão 8.0, da Golden Software, In ${ }^{\circledR}, 2002$, cujas colunas corresponderam ao método de interpolação da krigagem linear. A coluna do eixo “x” foi construída para representar o dia (em horas) da observação por cada período e no eixo " $y$ ” foram lançados os dados de umidade e de temperatura. A partir da interpolação, foi gerado o painel temporal-espacial.

\section{Análise e Interpretação dos Resultados}

\subsection{Análise da variabilidade térmica diária}

Por meio da aplicação da estatística descritiva foi possível descrever o comportamento das áreas a partir da unidade de análise do dia e da hora apresentando a temperatura do $\operatorname{ar}\left({ }^{\circ} \mathrm{C}\right)$ e a umidade relativa do ar $(\%)$ em suas médias, máximas, mínimas e desvio padrão. E através dos painéis Têmporo-Espaciais pode se observar a dinâmica climática que ocorreu entre os 31 dias analisados e comportamento dos elementos, tanto de temperatura como de umidade relativa no ciclo diurno e noturno.

No inverno a temperatura média para a estação em cada área foi de $14,3^{\circ} \mathrm{C}, 13,9^{\circ} \mathrm{C}, 13,8^{\circ} \mathrm{C}$ para a área 1,2 e 3 , respectivamente. Representando uma diferença de $0,4^{\circ} \mathrm{C}$ entre a lavoura e o banhado, $0,5^{\circ} \mathrm{C}$ entre a lavoura e o fragmento florestal, e $0,1^{\circ} \mathrm{C}$ entre o banhado e o fragmento florestal, conforme pode ser visualizado na Tabela 2.

Tabela 2 - Temperatura do ar $\left({ }^{\circ} \mathrm{C}\right)$ com a máxima absoluta, média e mínima absoluta de cada dia no mês de julho, e as suas médias e desvios padrões (D.P) totais de cada área, representativos do verão.

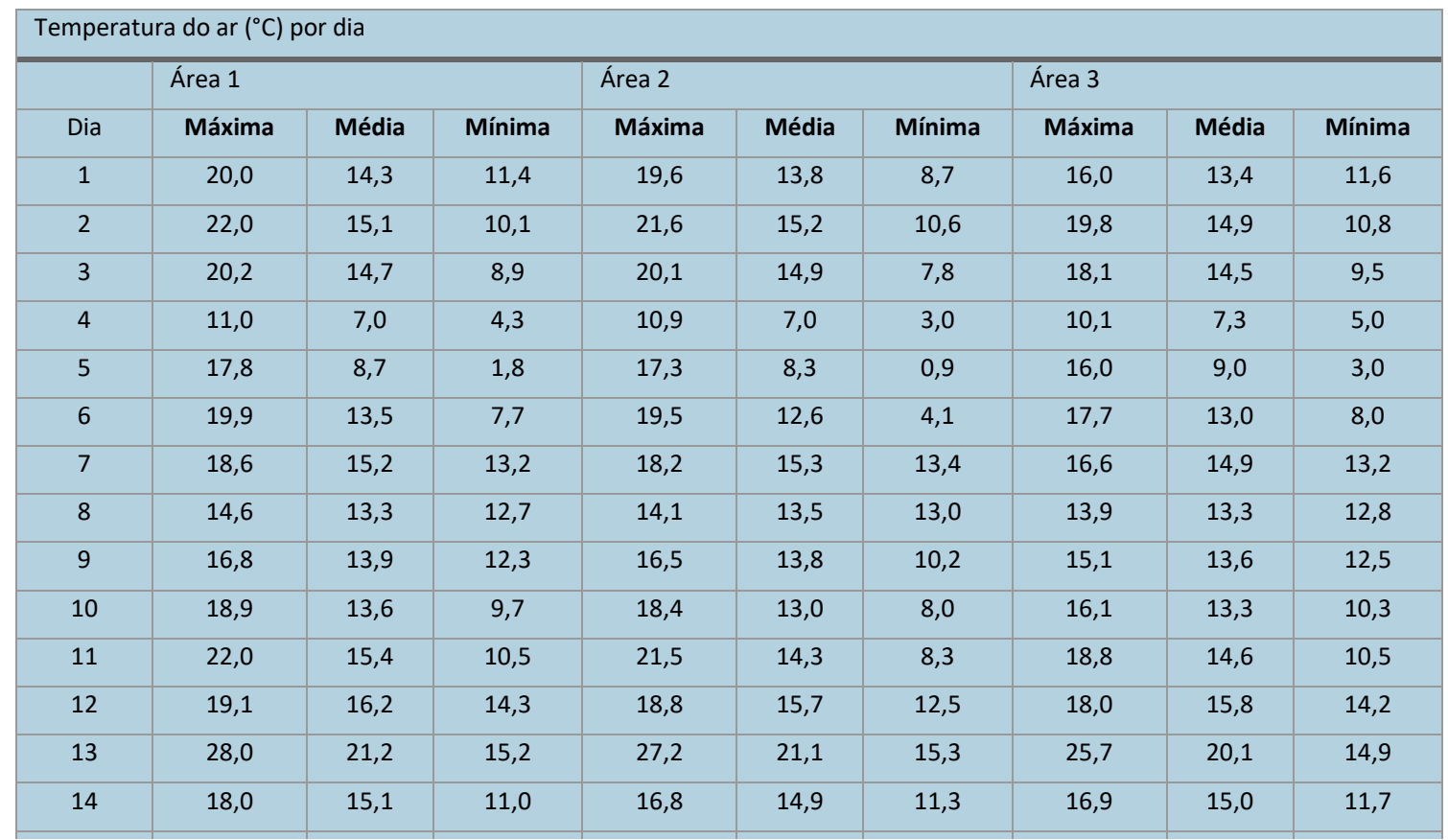

(Continuação) 
Tabela 2 - Continuação

\begin{tabular}{|c|c|c|c|c|c|c|c|c|c|}
\hline \multirow[b]{2}{*}{ Dia } & \multicolumn{3}{|l|}{ Área 1} & \multicolumn{3}{|l|}{ Área 2} & \multicolumn{3}{|l|}{ Área 3} \\
\hline & Máxima & Média & Mínima & Máxima & Média & Mínima & Máxima & Média & Mínima \\
\hline 15 & 11,4 & 9,7 & 8,6 & 11,9 & 10,3 & 9,3 & 11,9 & 10,2 & 9,1 \\
\hline 16 & 15,1 & 11,6 & 8,8 & 15,0 & 12,1 & 9,4 & 14,0 & 11,6 & 9,2 \\
\hline 17 & 17,8 & 13,8 & 9,0 & 17,3 & 13,7 & 9,5 & 15,5 & 13,5 & 10,1 \\
\hline 18 & 22,8 & 14,4 & 6,9 & 22,2 & 14,1 & 6,6 & 19,0 & 13,5 & 7,8 \\
\hline 19 & 26,0 & 20,3 & 15,0 & 25,0 & 19,4 & 12,8 & 23,0 & 18,8 & 14,1 \\
\hline 20 & 19,9 & 16,7 & 11,6 & 19,6 & 16,5 & 12,2 & 19,0 & 16,4 & 12,3 \\
\hline 21 & 16,9 & 11,5 & 7,7 & 16,0 & 11,6 & 6,5 & 14,2 & 11,3 & 8,6 \\
\hline 22 & 17,9 & 11,9 & 7,6 & 17,0 & 11,9 & 8,3 & 15,6 & 11,5 & 8,3 \\
\hline 23 & 18,3 & 12,2 & 8,5 & 18,0 & 12,0 & 7,1 & 17,2 & 12,0 & 9,3 \\
\hline 24 & 15,0 & 12,5 & 9,9 & 14,8 & 12,1 & 9,1 & 13,5 & 12,1 & 10,2 \\
\hline 25 & 18,1 & 13,9 & 10,8 & 17,3 & 13,3 & 8,7 & 16,2 & 13,5 & 11,2 \\
\hline 26 & 17,7 & 12,8 & 8,6 & 17,1 & 12,2 & 6,1 & 15,5 & 12,5 & 9,1 \\
\hline 27 & 23,2 & 14,8 & 8,8 & 22,6 & 14,1 & 6,8 & 20,1 & 13,9 & 9,8 \\
\hline 28 & 26,5 & 15,8 & 8,5 & 26,1 & 14,3 & 6,0 & 22,9 & 14,5 & 8,8 \\
\hline 29 & 26,5 & 17,6 & 12,1 & 26,1 & 15,9 & 8,9 & 23,2 & 16,1 & 11,6 \\
\hline 30 & 28,8 & 18,9 & 12,5 & 28,2 & 16,7 & 9,2 & 25,2 & 17,0 & 12,2 \\
\hline 31 & 27,1 & 19,3 & 12,7 & 26,6 & 17,3 & 9,3 & 23,8 & 17,6 & 12,4 \\
\hline $\begin{array}{l}\text { Média } \\
\text { Total }\end{array}$ & 19,9 & 14,3 & 10,0 & 19,4 & 13,9 & 8,8 & 17,7 & 13,8 & 10,4 \\
\hline D.P & 4,5 & 3,1 & 2,9 & 4,4 & 2,8 & 3,0 & 3,8 & 2,6 & 2,5 \\
\hline
\end{tabular}

Fonte: Dataloggers instalados em campo (2016)

Observa-se que há uma variação menor da temperatura média entre as áreas, e apesar da pouca diferença foi possível identificar que o fragmento florestal permaneceu com as suas temperaturas inferiores comparadas às demais. Através da Figura 5 é possível verificar que o inverno apresenta uma curva de desvio padrão da temperatura do ar entre as áreas com um comportamento mais próximo, ou seja, com pouca variação. Apresenta dias com picos de maior distanciamento em que o banhado se portou de forma mais heterogêneo e o fragmento florestal de forma mais homogêneo entre os três.

Reação que pôde ser evidenciada também pela amplitude térmica analisada nas temperaturas máximas e mínimas da média total para a estação, sendo $9,9^{\circ} \mathrm{C}$ na área $1,10,6^{\circ} \mathrm{C}$ na área e $7,3^{\circ} \mathrm{C}$ na área 3 .

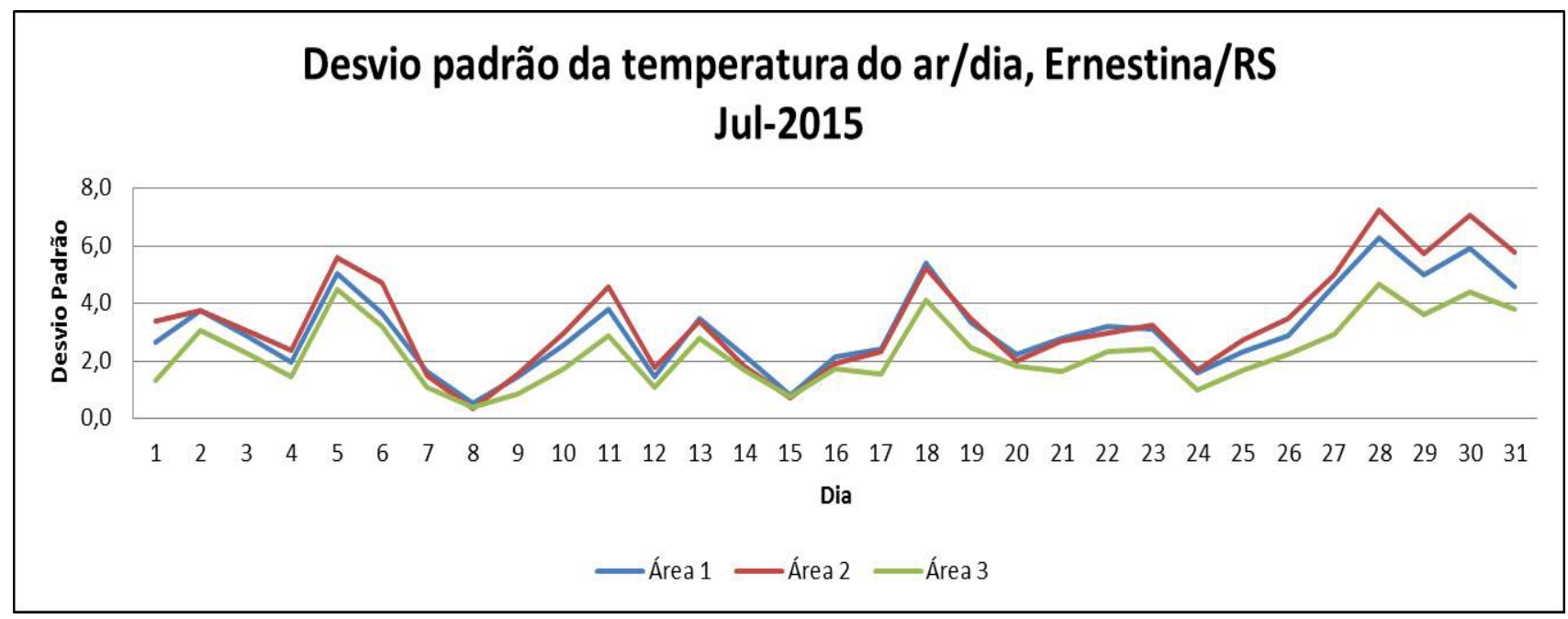

Figura 5- Desvio padrão da temperatura do ar

Fonte: Dataloggers instalados em campo (2016) 


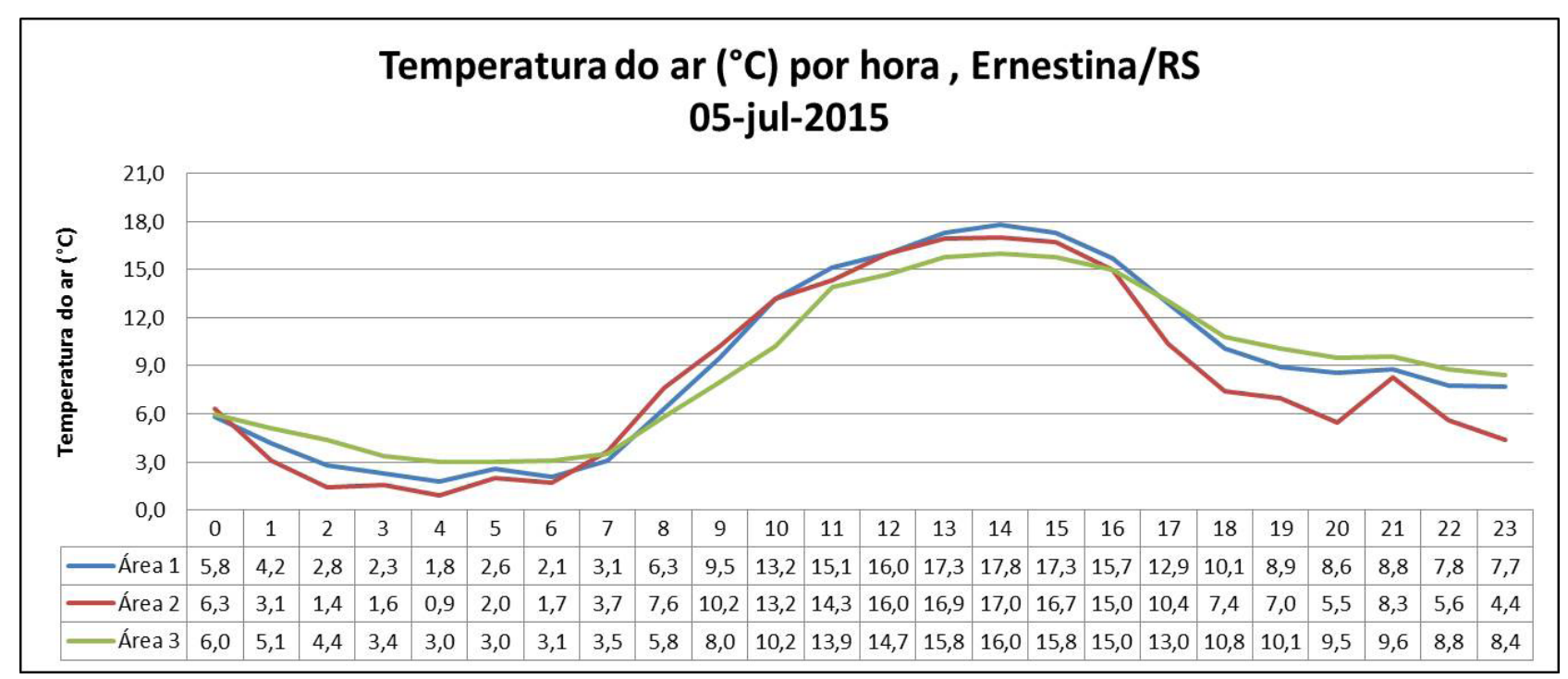

A temperatura mais baixa para a estação ocorreu no dia 05 de julho, com $1,8^{\circ} \mathrm{C}$ para a área $1,0,9^{\circ} \mathrm{C}$ a área 2 e $3,0^{\circ} \mathrm{C}$ a área 3 (Figura 6). Para esse dia, a área de banhado foi a que apresentou as temperaturas mais baixas durante a noite.

Figura 6- Temperatura do ar absoluta, dentro das 24 horas do dia 05 de julho de 2015.

Fonte: Dataloggers instalados em campo (2016).

As temperaturas mais elevadas desta estação foram registradas em dois dias: dia 13 e 30 de julho. A área de fragmento florestal apresentou a sua temperatura máxima para a estação no dia 13 , com o registro de $25,7^{\circ} \mathrm{C}$. Apesar do registro de sua temperatura extrema para a estação ocorrer nesse dia, ela ainda se manteve com a temperatura amena em comparação as outras duas áreas. como pode se visto na Figura 7

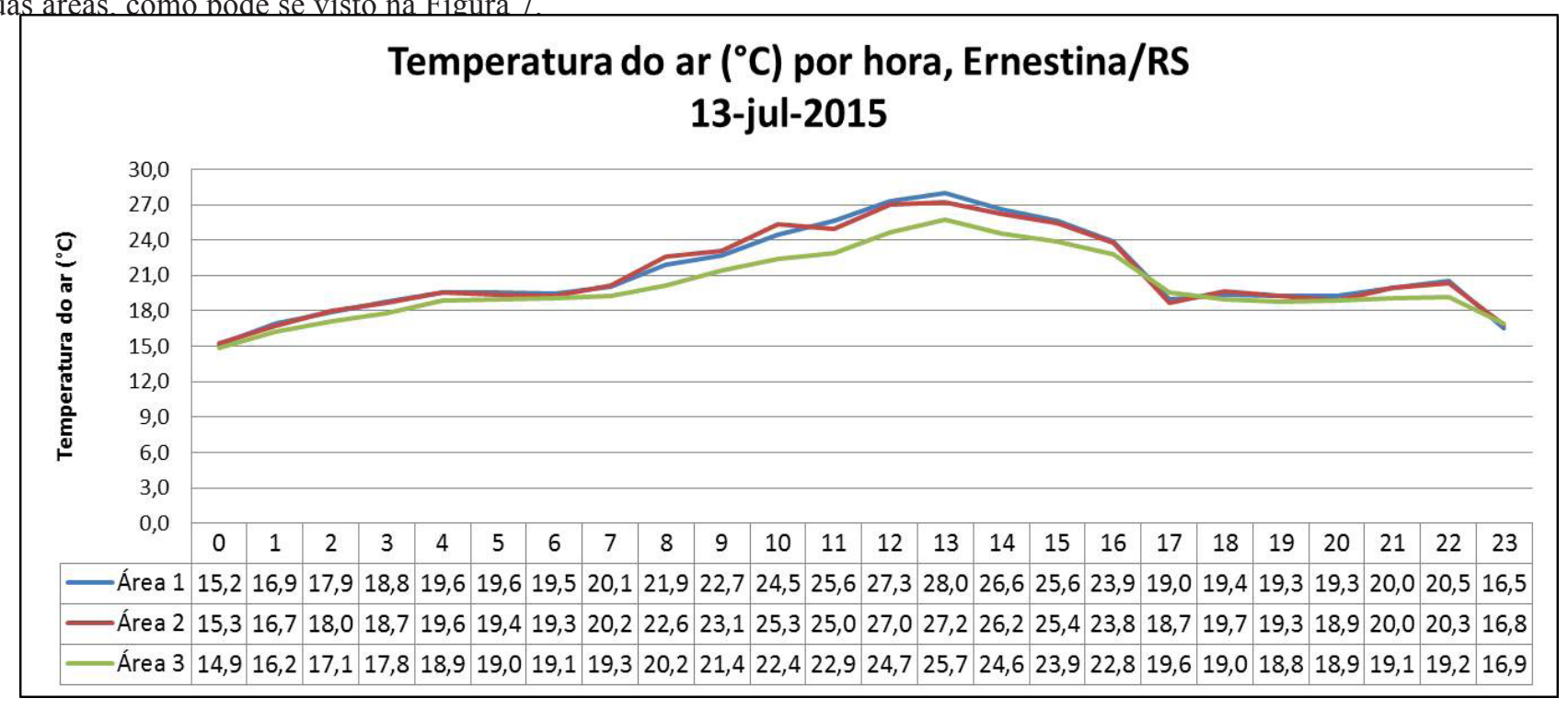

Figura 7- Temperatura do ar absoluta, dentro das 24 horas do dia 13 de julho de 2015.

Fonte: Dataloggers instalados em campo (2016)

Percebem-se através da Figura 7 que os valores da temperatura se mantiveram próximos entre as áreas ocorrendo uma variação mais acentuada no período entre às 7 horas e 17 horas. A amplitude térmica apresentada nas áreas foi de $12,8^{\circ} \mathrm{C}$ na lavoura, $11,9^{\circ} \mathrm{C}$ no banhado e $10,8^{\circ} \mathrm{C}$ no fragmento florestal. As áreas de lavoura e banhado marcaram suas temperaturas mais elevadas para a estação de inverno no dia 30 de julho com $28,8^{\circ} \mathrm{C}$ e $28,0^{\circ} \mathrm{C}$ respectivamente (Figura 8 ). Analisando as tempe- 


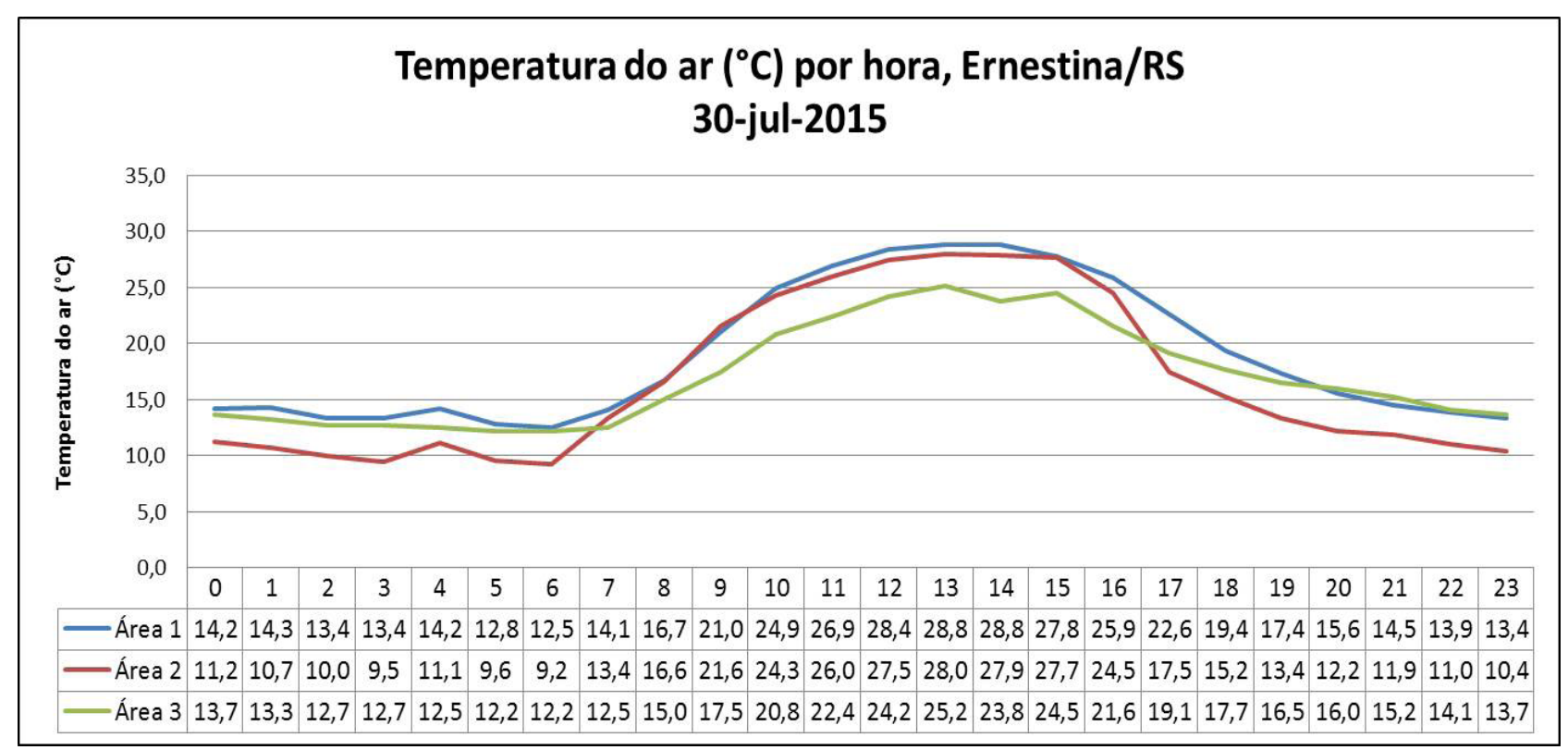

raturas máximas para esse dia nas três áreas, a lavoura foi a que apresentou a temperatura mais elevada, com uma diferença de $0,8^{\circ} \mathrm{C}$ para o banhado e $3,6^{\circ} \mathrm{C}$ para a área 3 . A partir desta informação, se comprovou o comportamento do ciclo noturno e diurno no fragmento florestal. Nessa área a oscilação na temperatura foi a menor comparadas às outras duas áreas. Figura 8- Temperatura do ar absoluta, dentro das 24 horas do dia 30 de julho de 2015.

Fonte: Dataloggers instalados em campo (2016)

\subsection{Análise da variabilidade térmica horária}

Para a compreensão do comportamento de variação dentro das 24 horas do dia na estação do inverno foi analisada a temperatura máxima absoluta, média e mínima absoluta em cada área. No inverno se observa, através da Figura 9, que o ciclo de aquecimento da temperatura ocorre mais intensamente a partir das 7 horas e o seu resfriamento tem inicio a partir das 16 horas.

$\mathrm{Na}$ análise das horas identificaram-se dois horários com maior concentração das temperaturas extremas. O primeiro horário ocorre às 4 horas com o comportamento de frio mais acentuado. As temperaturas foram de $1,8^{\circ} \mathrm{C}$ para a lavoura, $0,9^{\circ} \mathrm{C}$ para $\mathrm{o}$

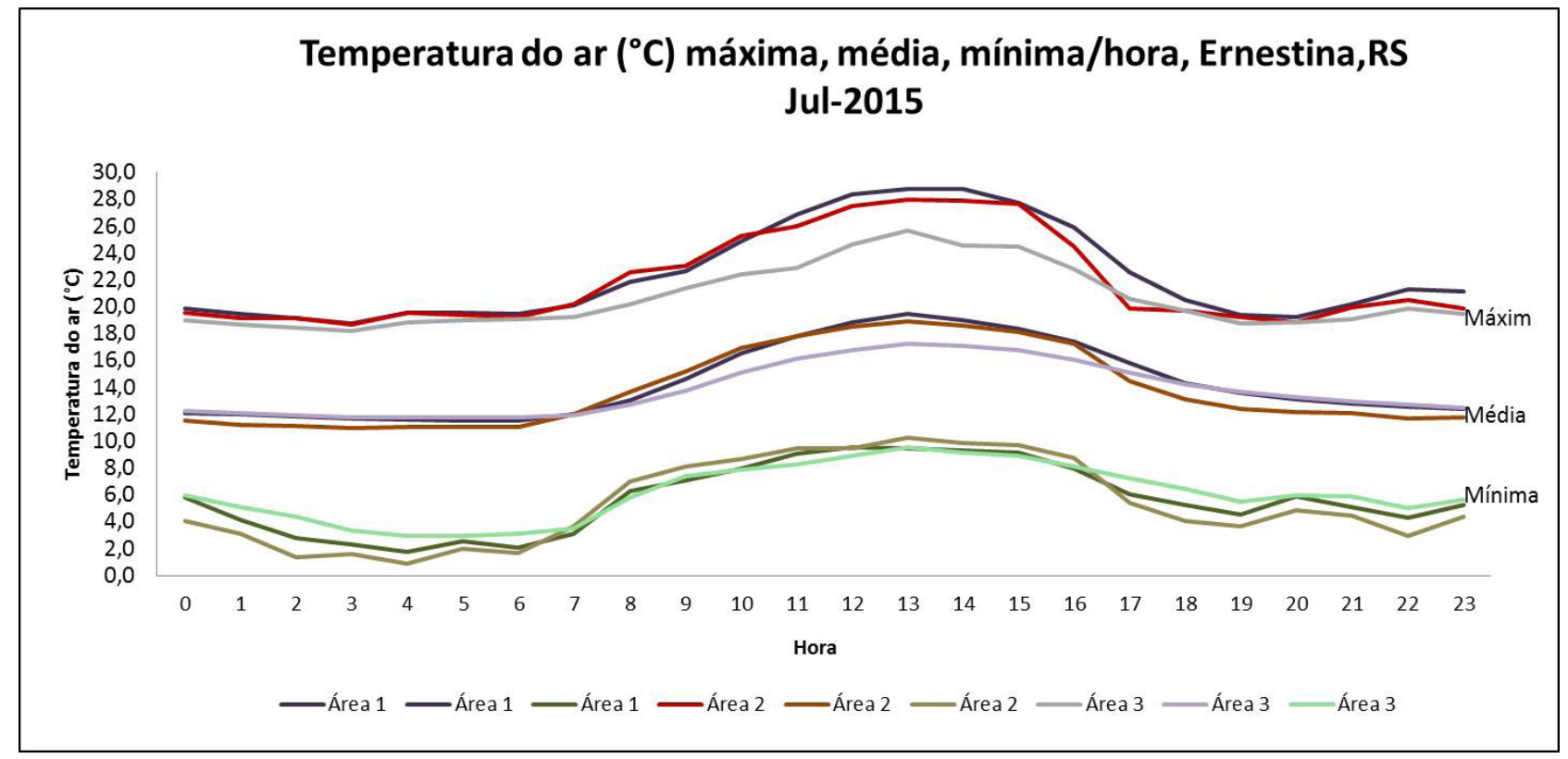

banhado e $3,0^{\circ} \mathrm{C}$ para o fragmento florestal.

$\mathrm{O}$ segundo horário acontece às 13 horas apresentando temperaturas mais elevadas de $28,8^{\circ} \mathrm{C}, 28^{\circ} \mathrm{C}$ e $25,7^{\circ} \mathrm{C}$ para as áreas 
1,2 e 3, respectivamente, como pode ser observado na Tabela 3.

Figura 9 - Temperatura do ar máxima absoluta, média e mínima absoluta por hora em cada área durante o inverno.

Fonte: Dataloggers instalados em campo (2016)

Tabela 3 - Temperatura do ar $\left({ }^{\circ} \mathrm{C}\right)$ máxima absoluta, máxima média e mínima absoluta, por hora e as suas médias e desvios padrões (D.P) totais de cada área, representativos do inverno.

O cálculo do desvio padrão dentro das 24 horas do mês de julho nos permite inferir o padrão de variação da temperatura noturna e diurna em cada área (Figura 10). A área 3, assim como no verão, apresentou registros mais homogêneos, sofrendo menos interferência dos elementos climáticos. No turno da noite, o banhado se apresentou mais heterogêneo do que as demais áreas, com maiores variações em suas temperaturas. No turno do dia, a lavoura apresentou mais heterogeneidade, com pouca diferença para o banhado.

Figura 10 - Desvio padrão da temperatura do ar por hora nas áreas.

Fonte: Dataloggers instalados em campo (2016)

\subsection{Análise da variabilidade higrométrica diária}

No inverno a média de umidade relativa do ar para a estação ficou em 95,6 \% para a lavoura, 96,4 \% para o banhado e 95,7\% para o fragmento florestal (Tabela 4). Apresentando uma diferença de 0,8 entre a área 1 e 2 , de $0,1 \%$ entre a área 1 e 3, e 0,7 entre a área 2 e 3.

\begin{tabular}{|c|c|c|c|c|c|c|c|c|c|}
\hline \multicolumn{10}{|c|}{ Temperatura do $\operatorname{ar}\left({ }^{\circ} \mathrm{C}\right)$ por hora } \\
\hline \multirow[b]{2}{*}{ Hora } & \multicolumn{3}{|c|}{ Área 1} & \multicolumn{3}{|c|}{ Área 2} & \multicolumn{3}{|c|}{ Área 3} \\
\hline & Máxima & Média & Mínima & Máxima & Média & Mínima & Máxima & Média & Mínima \\
\hline 0 & 19,9 & 12,1 & 5,8 & 19,6 & 11,5 & 4,1 & 19,0 & 12,2 & 6,0 \\
\hline 1 & 19,5 & 12,1 & 4,2 & 19,2 & 11,2 & 3,1 & 18,7 & 12,1 & 5,1 \\
\hline 2 & 19,2 & 11,8 & 2,8 & 19,2 & 11,1 & 1,4 & 18,5 & 12,0 & 4,4 \\
\hline 3 & 18,8 & 11,7 & 2,3 & 18,7 & 11,0 & 1,6 & 18,2 & 11,8 & 3,4 \\
\hline 4 & 19,6 & 11,6 & 1,8 & 19,6 & 11,1 & 0,9 & 18,9 & 11,8 & 3,0 \\
\hline 5 & 19,6 & 11,6 & 2,6 & 19,4 & 11,1 & 2,0 & 19,0 & 11,8 & 3,0 \\
\hline 6 & 19,5 & 11,5 & 2,1 & 19,3 & 11,1 & 1,7 & 19,1 & 11,8 & 3,1 \\
\hline 7 & 20,1 & 12,0 & 3,1 & 20,2 & 12,0 & 3,7 & 19,3 & 11,9 & 3,5 \\
\hline 8 & 21,9 & 13,1 & 6,3 & 22,6 & 13,7 & 7,0 & 20,2 & 12,7 & 5,8 \\
\hline 9 & 22,7 & 14,7 & 7,1 & 23,1 & 15,2 & 8,1 & 21,4 & 13,8 & 7,4 \\
\hline 10 & 24,9 & 16,6 & 8,0 & 25,3 & 17,0 & 8,7 & 22,4 & 15,2 & 7,9 \\
\hline 11 & 26,9 & 17,8 & 9,1 & 26,0 & 17,9 & 9,5 & 22,9 & 16,1 & 8,3 \\
\hline 12 & 28,4 & 18,9 & 9,6 & 27,5 & 18,6 & 9,5 & 24,7 & 16,8 & 8,9 \\
\hline 13 & 28,8 & 19,5 & 9,5 & 28,0 & 18,9 & 10,3 & 25,7 & 17,3 & 9,6 \\
\hline 14 & 28,8 & 19,0 & 9,3 & 27,9 & 18,7 & 9,9 & 24,6 & 17,1 & 9,2 \\
\hline 15 & 27,8 & 18,4 & 9,2 & 27,7 & 18,1 & 9,7 & 24,5 & 16,8 & 8,9 \\
\hline 16 & 25,9 & 17,4 & 8,0 & 24,5 & 17,2 & 8,8 & 22,8 & 16,1 & 8,1 \\
\hline 17 & 22,6 & 15,9 & 6,1 & 19,9 & 14,5 & 5,4 & 20,6 & 15,1 & 7,3 \\
\hline 18 & 20,5 & 14,4 & 5,3 & 19,7 & 13,2 & 4,1 & 19,7 & 14,2 & 6,5 \\
\hline
\end{tabular}

(Continua) 
Tabela 3 - continuação

\begin{tabular}{|c|c|c|c|c|c|c|c|c|c|}
\hline \multicolumn{8}{|c|}{ Temperatura do ar $\left(^{\circ} \mathbf{C}\right.$ ) por hora } \\
\hline & Área 1 & \multicolumn{3}{|c|}{ Área 2 } & & Área 3 \\
\hline Hora & Máxima & Média & Mínima & Máxima & Média & Mínima & Máxima & Média & Mínima \\
\hline $\mathbf{1 9}$ & 19,4 & 13,6 & 4,6 & 19,3 & 12,4 & 3,7 & 18,8 & 13,7 & 5,5 \\
\hline $\mathbf{2 0}$ & 19,3 & 13,2 & 5,9 & 18,9 & 12,2 & 4,9 & 18,9 & 13,3 & 6,0 \\
\hline $\mathbf{2 1}$ & 20,2 & 12,9 & 5,1 & 20,0 & 12,1 & 4,5 & 19,1 & 13,0 & 5,9 \\
\hline $\mathbf{2 2}$ & 21,3 & 12,6 & 4,3 & 20,5 & 11,8 & 3,0 & 19,9 & 12,7 & 5,0 \\
\hline $\mathbf{2 3}$ & 21,2 & 12,4 & 5,3 & 19,9 & 11,8 & 4,4 & 19,5 & 12,5 & 5,7 \\
\hline $\begin{array}{c}\text { Média } \\
\text { total }\end{array}$ & 22,4 & 14,4 & 5,7 & 21,9 & 13,9 & 5,4 & 20,7 & 13,8 & 6,1 \\
\hline D.P & 3,43 & 2,73 & 2,50 & 3,30 & 2,89 & 3,07 & 2,28 & 1,92 & 2,05 \\
\hline
\end{tabular}

Analisando a distribuição da umidade relativa do ar entre as áreas em cada dia do mês julho, constata-se que houve dias de maior influência de movimentos de massas de ar, causando variações mais intensas na umidade entre o turno da noite e do dia. Destacando os dois dias mais extremos, dia 05 e 30 de julho, é possível perceber esta oscilação ao longo de cada dia (Figura 11). Ao longo do dia 05 a lavoura variou de 93,1 a $57,2 \%$, o banhado de 95,4 a $58 \%$ e no fragmento florestal de 91,1 a $62 \%$.

\section{Desvio padrão da temperatura do ar/hora, Ernestina/RS Jul-2015}

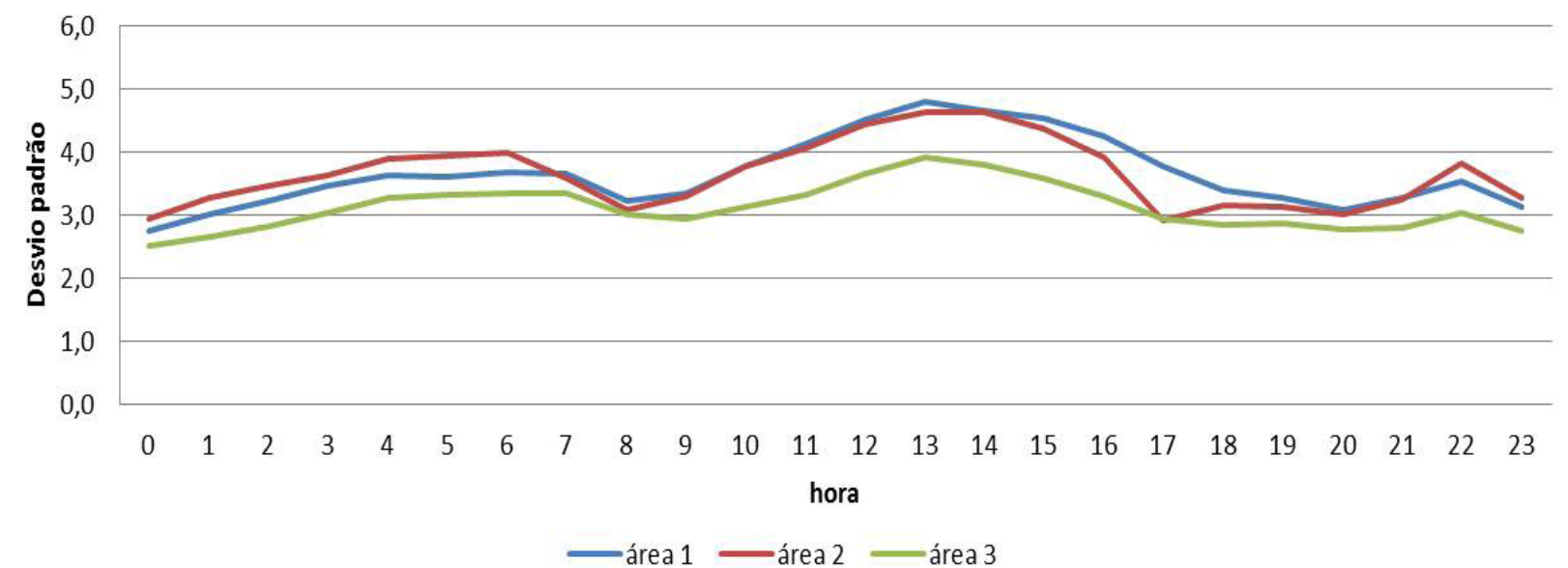

No dia 30 de 96 a 40,3\% na área 1, de 97,1 a 46,4\% na área 2 e de 94,5 a 55\% na área 3.

Figura 114 - Umidade relativa do ar máxima e mínima para cada dia nas áreas.

Fonte: Dataloggers instalados em campo (2016)

\subsection{Análise da variabilidade higrométrica horária}

A maior concentração de umidade foi encontrada no período da noite e da manhã. Dentro das máximas analisadas os horários de maior umidade foram entre as 7 e 9 horas para a área 1, com 97,1\%, entre 7 e 8 horas para a área 2, com 97,2\%, e às 10 horas para a área $3 \mathrm{com} 97,5 \%$. E o período de menor umidade se concentrou na parte da tarde entre 14 e 15 horas, com 40,3\% na área 1, 46,4\% na área 2 e 55\% na área 3 (Figura 11 e Tabela 5).

Figura 115 - Umidade relativa do ar por hora em cada área, no inverno.

Fonte: Dataloggers instalados em campo (2016)

O fragmento florestal no inverno foi o que se apresentou com a umidade relativa do ar mais elevada, seguido do banhado 
Tabela 4 -1Exposição da umidade relativa do ar em máxima absoluta, média e mínima absoluta para cada dia do mês de julho, com a sua média e desvio padrão.

\begin{tabular}{|c|c|c|c|c|c|c|c|c|c|}
\hline \multicolumn{10}{|c|}{ Umidade relativa do ar (\%) por hora } \\
\hline \multirow[b]{2}{*}{ Hora } & \multicolumn{3}{|c|}{ Área 1} & \multicolumn{3}{|c|}{ Área 2} & \multicolumn{3}{|c|}{ Área 3} \\
\hline & Máxima & Média & Mínima & Máxima & Média & Mínima & Máxima & Média & Mínima \\
\hline 0 & 96,6 & 93,2 & 74,2 & 96,9 & 94,1 & 77,6 & 96,5 & 94,1 & 82,9 \\
\hline 1 & 96,7 & 93,3 & 76,4 & 97,1 & 94,3 & 79,0 & 96,9 & 94,1 & 83,5 \\
\hline 2 & 96,8 & 93,1 & 77,0 & 97,2 & 94,1 & 78,6 & 97,0 & 94,1 & 83,6 \\
\hline 3 & 96,8 & 93,4 & 78,9 & 96,9 & 94,4 & 82,1 & 96,9 & 94,1 & 84,4 \\
\hline 4 & 96,9 & 93,1 & 79,4 & 97,1 & 94,4 & 82,4 & 97,0 & 94,2 & 83,9 \\
\hline 5 & 96,9 & 93,4 & 79,7 & 97,2 & 94,5 & 80,3 & 96,9 & 94,3 & 84,7 \\
\hline 6 & 97,0 & 93,2 & 80,2 & 97,1 & 94,4 & 80,3 & 96,9 & 94,3 & 85,5 \\
\hline 7 & 97,1 & 92,6 & 79,8 & 97,2 & 94,2 & 80,5 & 97,0 & 94,3 & 84,1 \\
\hline 8 & 97,1 & 91,5 & 79,6 & 97,2 & 91,5 & 78,7 & 97,1 & 94,1 & 83,9 \\
\hline 9 & 97,1 & 88,4 & 76,9 & 97,1 & 87,4 & 73,2 & 97,2 & 92,9 & 81,5 \\
\hline 10 & 96,1 & 84,2 & 66,8 & 96,0 & 82,9 & 65,1 & 97,5 & 90,0 & 79,4 \\
\hline 11 & 96,3 & 79,4 & 56,2 & 96,2 & 79,9 & 61,7 & 97,2 & 87,1 & 67,7 \\
\hline 12 & 95,9 & 76,7 & 50,8 & 95,8 & 77,5 & 56,0 & 97,1 & 84,8 & 63,8 \\
\hline 13 & 95,8 & 75,5 & 43,5 & 95,5 & 76,3 & 47,1 & 97,1 & 84,1 & 62,3 \\
\hline 14 & 95,9 & 75,5 & 40,3 & 95,7 & 76,6 & 47,0 & 97,1 & 84,4 & 62,0 \\
\hline 15 & 96,0 & 77,7 & 44,4 & 95,8 & 78,6 & 46,4 & 97,0 & 85,5 & 55,0 \\
\hline 16 & 95,9 & 81,5 & 54,6 & 95,7 & 82,2 & 58,6 & 96,9 & 88,1 & 70,1 \\
\hline 17 & 96,2 & 85,8 & 60,4 & 96,0 & 89,9 & 76,5 & 96,5 & 90,7 & 77,5 \\
\hline 18 & 96,2 & 88,4 & 68,3 & 95,9 & 92,4 & 79,3 & 96,6 & 92,2 & 79,8 \\
\hline 19 & 96,2 & 90,5 & 76,9 & 96,3 & 93,6 & 87,3 & 96,5 & 92,9 & 83,4 \\
\hline 20 & 96,1 & 91,7 & 78,3 & 96,6 & 94,2 & 88,4 & 96,7 & 93,3 & 84,6 \\
\hline 21 & 96,4 & 91,8 & 72,4 & 96,5 & 93,5 & 82,1 & 96,5 & 93,2 & 83,3 \\
\hline 22 & 96,3 & 92,4 & 68,7 & 96,7 & 93,5 & 73,2 & 96,5 & 93,5 & 78,0 \\
\hline 23 & 96,6 & 92,7 & 68,1 & 97,0 & 93,9 & 75,7 & 96,5 & 93,7 & 79,7 \\
\hline Média & 96,5 & 87,9 & 68,0 & 96,5 & 89,1 & 72,4 & 96,9 & 91,4 & 77,7 \\
\hline D.P & 0,43 & 6,40 & 12,72 & 0,59 & 6,72 & 12,53 & 0,28 & 3,57 & 8,79 \\
\hline
\end{tabular}

Fonte: Dataloggers instalados em campo (2016).

e da lavoura. No banhado é possível verificar no comportamento da umidade que durante o dia ela decai se aproximando dos valores da lavoura e a partir das 16 horas, ela assume um padrão abrupto de elevação se aproximando dos valores de umidade do fragmento florestal. 


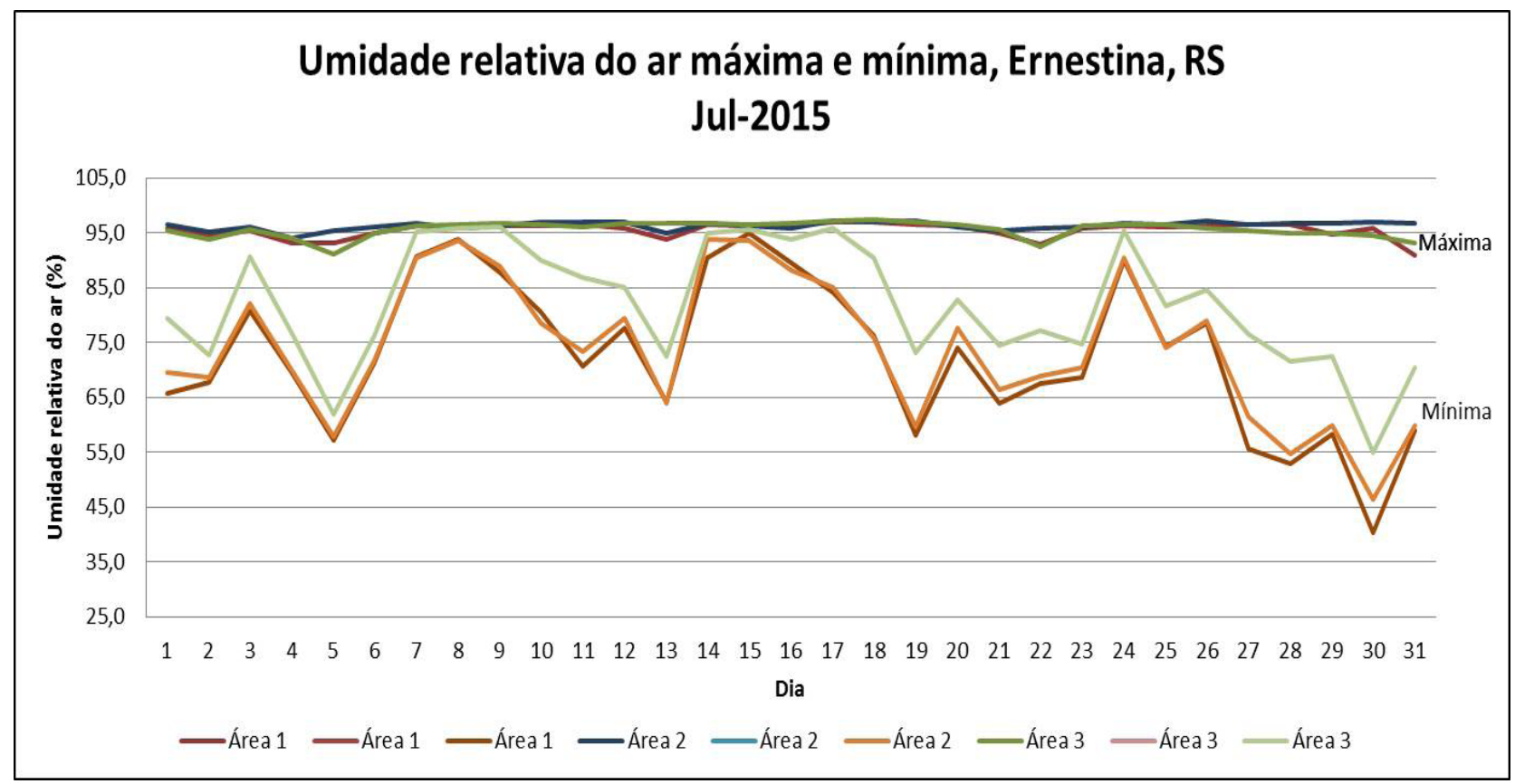

\subsection{Painéis têmporo-espaciais da variabilidade termo-higrométrica}

O ciclo diurno e noturno de variações na temperatura e umidade relativa do ar pode ser evidenciado através dos painéis têmporo-espaciais, que também evidenciam os dias em que ocorreram as maiores variações nas áreas, os dias extremos de frio e calor (Figura 12). Verificou-se que em certos horários houve maiores variações entre as áreas por interferência do ganho de energia demandado pela presença do sol que aqueceu as superfícies. E ao pôr do sol, ocorreu a perda de energia da superfície, rebaixando suas temperaturas com o inicio da noite nos três usos do solo.

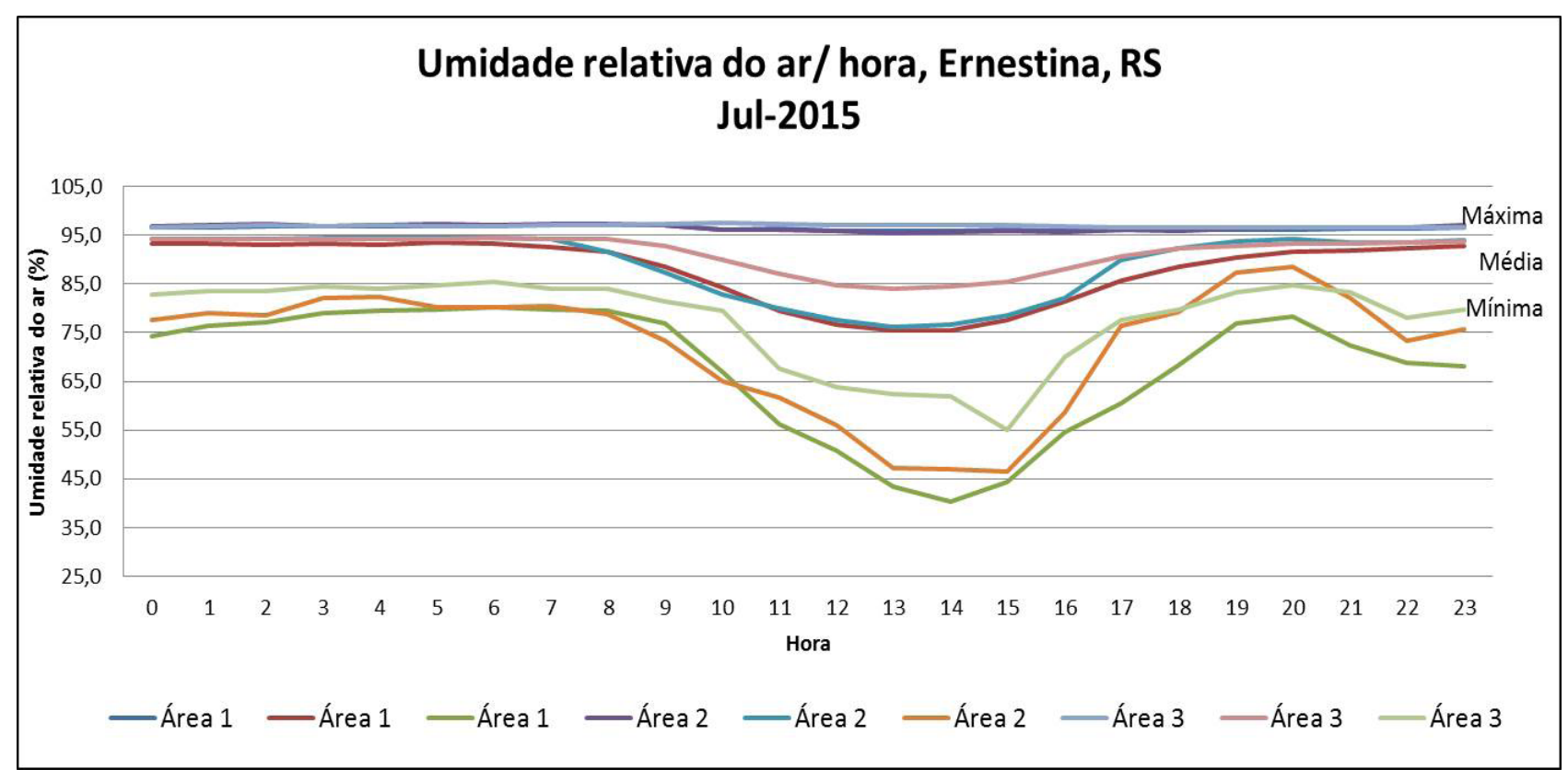


Tabela 5 - Umidade relativa do ar dentro por hora nas três áreas de estudo.

\begin{tabular}{|c|c|c|c|c|c|c|c|c|c|}
\hline \multicolumn{10}{|c|}{ Umidade relativa do ar (\%) por hora } \\
\hline \multirow[b]{2}{*}{ Hora } & \multicolumn{3}{|c|}{ Área 1} & \multicolumn{3}{|c|}{ Área 2} & \multicolumn{3}{|c|}{ Área 3} \\
\hline & Máxima & Média & Mínima & Máxima & Média & Mínima & Máxima & Média & Mínima \\
\hline 0 & 96,6 & 93,2 & 74,2 & 96,9 & 94,1 & 77,6 & 96,5 & 94,1 & 82,9 \\
\hline 1 & 96,7 & 93,3 & 76,4 & 97,1 & 94,3 & 79,0 & 96,9 & 94,1 & 83,5 \\
\hline 2 & 96,8 & 93,1 & 77,0 & 97,2 & 94,1 & 78,6 & 97,0 & 94,1 & 83,6 \\
\hline 3 & 96,8 & 93,4 & 78,9 & 96,9 & 94,4 & 82,1 & 96,9 & 94,1 & 84,4 \\
\hline 4 & 96,9 & 93,1 & 79,4 & 97,1 & 94,4 & 82,4 & 97,0 & 94,2 & 83,9 \\
\hline 5 & 96,9 & 93,4 & 79,7 & 97,2 & 94,5 & 80,3 & 96,9 & 94,3 & 84,7 \\
\hline 6 & 97,0 & 93,2 & 80,2 & 97,1 & 94,4 & 80,3 & 96,9 & 94,3 & 85,5 \\
\hline 7 & 97,1 & 92,6 & 79,8 & 97,2 & 94,2 & 80,5 & 97,0 & 94,3 & 84,1 \\
\hline 8 & 97,1 & 91,5 & 79,6 & 97,2 & 91,5 & 78,7 & 97,1 & 94,1 & 83,9 \\
\hline 9 & 97,1 & 88,4 & 76,9 & 97,1 & 87,4 & 73,2 & 97,2 & 92,9 & 81,5 \\
\hline 10 & 96,1 & 84,2 & 66,8 & 96,0 & 82,9 & 65,1 & 97,5 & 90,0 & 79,4 \\
\hline 11 & 96,3 & 79,4 & 56,2 & 96,2 & 79,9 & 61,7 & 97,2 & 87,1 & 67,7 \\
\hline 12 & 95,9 & 76,7 & 50,8 & 95,8 & 77,5 & 56,0 & 97,1 & 84,8 & 63,8 \\
\hline 13 & 95,8 & 75,5 & 43,5 & 95,5 & 76,3 & 47,1 & 97,1 & 84,1 & 62,3 \\
\hline 14 & 95,9 & 75,5 & 40,3 & 95,7 & 76,6 & 47,0 & 97,1 & 84,4 & 62,0 \\
\hline 15 & 96,0 & 77,7 & 44,4 & 95,8 & 78,6 & 46,4 & 97,0 & 85,5 & 55,0 \\
\hline 16 & 95,9 & 81,5 & 54,6 & 95,7 & 82,2 & 58,6 & 96,9 & 88,1 & 70,1 \\
\hline 17 & 96,2 & 85,8 & 60,4 & 96,0 & 89,9 & 76,5 & 96,5 & 90,7 & 77,5 \\
\hline 18 & 96,2 & 88,4 & 68,3 & 95,9 & 92,4 & 79,3 & 96,6 & 92,2 & 79,8 \\
\hline 19 & 96,2 & 90,5 & 76,9 & 96,3 & 93,6 & 87,3 & 96,5 & 92,9 & 83,4 \\
\hline 20 & 96,1 & 91,7 & 78,3 & 96,6 & 94,2 & 88,4 & 96,7 & 93,3 & 84,6 \\
\hline 21 & 96,4 & 91,8 & 72,4 & 96,5 & 93,5 & 82,1 & 96,5 & 93,2 & 83,3 \\
\hline 22 & 96,3 & 92,4 & 68,7 & 96,7 & 93,5 & 73,2 & 96,5 & 93,5 & 78,0 \\
\hline 23 & 96,6 & 92,7 & 68,1 & 97,0 & 93,9 & 75,7 & 96,5 & 93,7 & 79,7 \\
\hline Média & 96,5 & 87,9 & 68,0 & 96,5 & 89,1 & 72,4 & 96,9 & 91,4 & 77,7 \\
\hline D.P & 0,43 & 6,40 & 12,72 & 0,59 & 6,72 & 12,53 & 0,28 & 3,57 & 8,79 \\
\hline
\end{tabular}

Fonte: Dataloggers instalados em campo (2016). 

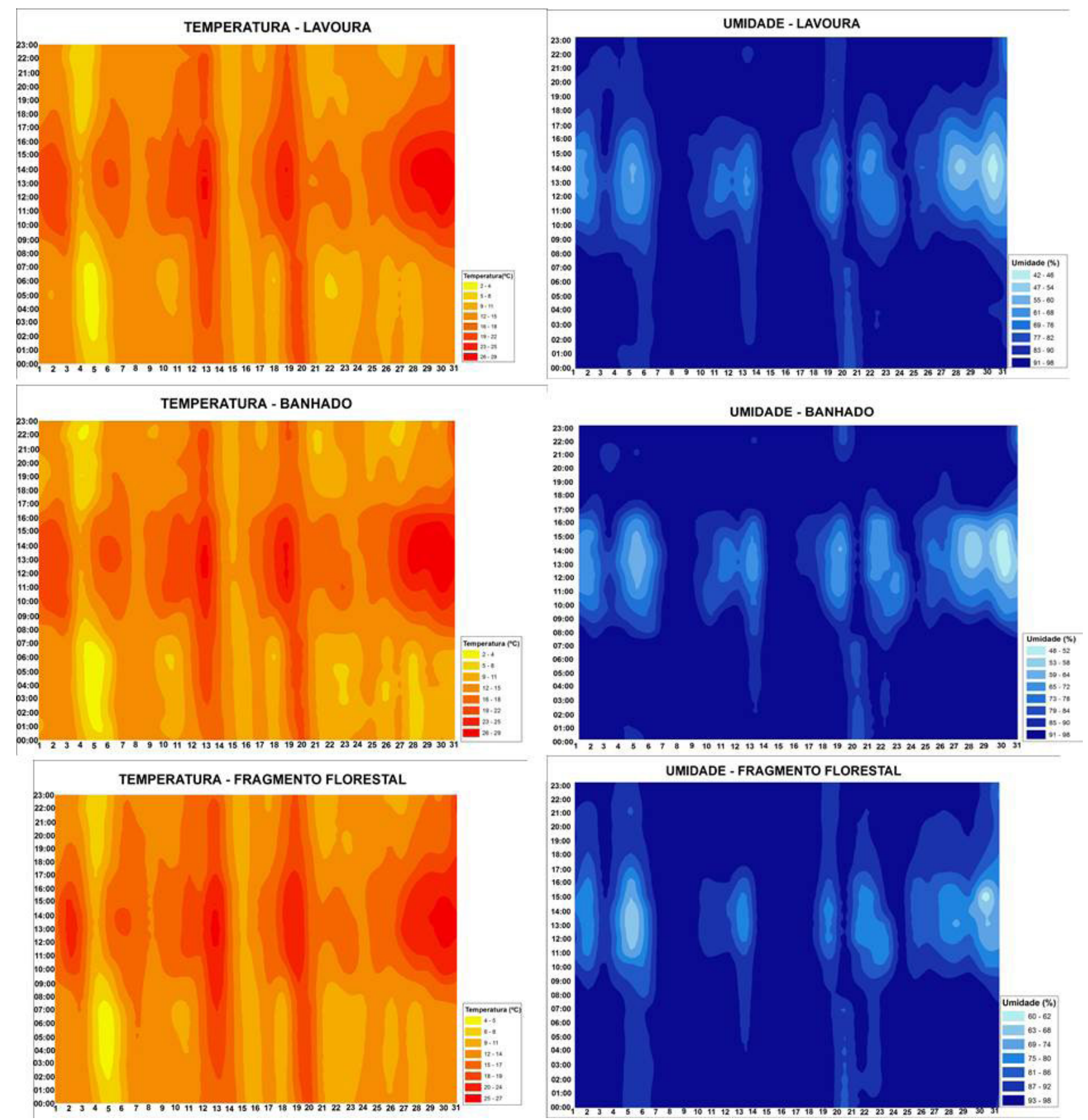

Figura 12 - Painéis Têmporo-Espaciais

Org.: Os autores (2017)

A umidade nem sempre acompanha perfeitamente e inversamente proporcional a variação da temperatura. No entanto, observa-se que os maiores valores de temperatura, e os menores de umidade relativa, concentram-se a partir do dia 27 de julho, bem como anteriormente, entre os dias 12 a 14 , e 19 a 21.

Nesses casos extremos de temperatura e umidade registrados, o uso do solo não torna-se um condicionante à variabilidade dos elementos do clima, pois as escalas superiores de controle climáticos sobrepõem-se, dominando todos os ambientes. Em outras palavras, o macroclima sobrepõe-se ao microclima. Nos demais dias do ano vê-se o uso do solo como principal condicionante da variabilidade termo-higrométrica no entorno do Reservatório Ernestina. 


\section{Conclusões}

A preocupação principal desta pesquisa foi compreender como os ambientes naturais ou como manejo agrícola pode propiciar variações na temperatura e na umidade de cada local. Após o desenvolvimento do estudo foi possível identificar algumas variações no comportamento termo-higrométrico entres três áreas

O fragmento florestal foi o que apresentou uma menor variação termo-higrométrica, sofrendo menor interferência dos elementos do clima sobre a sua área, tanto de noite como durante o dia. Tais resultados para a área 3 , corroboram os estudos de Lima (2009), quando mencionam que a as áreas arborizadas não só permitem um maior bloqueio de energia solar direta sobre a superfície, como também há uma maior disponibilidade de água, através do processo de evapotranspiração e evaporação, tornando estes ambientes mais úmidos e frios. A lavoura foi a que se apresentou com uma variação maior na temperatura e umidade, com temperaturas mais elevadas e umidade mais baixa.

Inseridos na preocupação de aprimorar elementos teóricos da Climatologia Geográfica em especial, no processo de interferência que os seres exercem sobre o clima, criando variações microclimáticas em determinados locais como ficou evidenciado na área de plantação durante o período este período de inverno em que o solo esteve mais exposto.

\section{Agradecimentos}

O presente trabalho foi realizado com apoio do Programa Nacional de Cooperação Acadêmica da Coordenação de Aperfeiçoamento de Pessoal de Nível Superior - CAPES/Brasil - No Processo: 88881.068465/2014/01 nº 071/2013 CAPES/PROCAD.

\section{Referências}

AYOADE, J. O. Introdução à climatologia para os trópicos. Rio de Janeiro: Bertrand Brasil, 6. Ed. 2003.

COMPANHIA ESTADUAL DE ENERGIA ELÉTRICA (CEEE-GT). Plano de uso e ocupação do solo no entorno do Reservatório da UHE Ernestina. Disponível em: www.ceee.com.br/pportal/ceee/Component/Controller. aspx?CC=29417. 2008. Acesso em 15 mar. 2015.

GEIGER, R. Manual de Microclimatologia - O clima da camada de ar junto ao solo. Lisboa: Fundação Calouste Gulbenkian, 1961. 556 p.

HOPPE, I. L.; IENSSE, A. C.; SIMIONI, J. P. D.; WOLLMANN, C. A. Comparação entre um abrigo meteorológico de baixo custo e a estação meteorológica oficial no INMET, em Santa Maria (RS). Revista Ciência \& Natura, v. 37, p. 132-137, 2015.

KAISER, E. A., CORREA DOS SANTOS, F., PEREIRA FILHO, W. Influência da precipitação pluviométrica e uso da terra em variáveis limnológicas do reservatório da usina Hidrelétrica Ernestina, RS. GeoFocus, no 16 , p. 3-22. 2015.

\section{LEPSCH, I. F. Formação e conservação do solo. São Paulo: Oficina de Textos, 2002.}

LIMA, N. G. B. Análise Microclimática dos Manguezais da Barra do Ribeira-Iguape/SP. Dissertação de Mestrado (Mestrado em Geografia Física). Universidade de São Paulo. São Paulo, 2009. 203p.

MENDONÇA, F. A.; DANNI-OLIVEIRA, I. M. Climatologia - Noções Básicas e Climas do Brasil. São Paulo: Oficina de Textos, 2007. 208p.

MONTEIRO, C. A. F. O estudo geográfico do clima. Cadernos Geográficos, nº1, maio. p. 07-72. 1999.

MONTEIRO, C. A. F. O Clima da Região Sul. In: Geografia Regional do Brasil: Região Sul. Rio de Janeiro: IBGE, v.4, p.117-169, 1963.

NIMER, E. Climatologia do Brasil. Rio de Janeiro, 2ª ed. IBGE, 1989. 
ORGANIZAÇÃO MUNDIAL METEOROLÓGICA (OMM). Manual global para processamento de dados e sistema de previsão. Genebra: Secretaria da Organização Mundial Meteorológica, 1992.

PREFEITURA MUNICIPAL DE ERNESTINA (PME). Histórico do Município de Ernestina. Disponível em: $<$ www.ernestina.rs.gov.br>>. Acesso em 15 abr. 2016.

RIBEIRO, A. G. As Escalas do Clima. Boletim de Geografia Teorética. Rio Claro, IGCE/UNESP, v 23, n 45 - 46. p. 288 - 294. 1993.

ROSSATO, M. S. Os climas do Rio Grande do Sul: variabilidade, tendências e tipologia. Tese (Doutorado em Geografia). Universidade Federal do Rio Grande do Sul. Porto Alegre, 2011.

SARTORI, M. G. B. A dinâmica do clima do Rio Grande do Sul: indução empírica e conhecimento científico. Revista Terra Livre, São Paulo, v. 1, n. 20, p. 27-49, jan./jul. 2003.

SEMC - SECRETARIA ESTADUAL DE MINAS, ENERGIA E COMUNICAÇÕES. Governo do Estado do Rio Grande do Sul. Atlas Eólico do Rio Grande do Sul. Porto Alegre, 2002. 65p.

SERAFINI JR., S. O Microclima de uma Vereda Degradada: Estudo de Caso no Parque Estadual Veredas do Peruaçu - MG. Tese (Doutorado em Geografia Física). Universidade de São Paulo. São Paulo, 2010. 140p.

SILVA, J.A; PAULA, F. N. Princípios básicos de dendrometria. Recife: UFRPE; 1979.

ZAVATTINI, J. A.; BOIN, M. N. Climatologia Geográfica - Teoria e Prática da Pesquisa. São Paulo: Alínea, 2013.

ZIANI, P.; PRINA, B. Z. . Análise multitemporal do uso e ocupação da terra da bacia hidrográfica do entorno da barragem de Ernestina/RS com imagens do sensor LANDSAT-TM 5. In: XVI Simpósio Brasileiro de Geografia Física Aplicada, 2015, Teresina - PI. ANAIS - XVI Simpósio Brasileiro de Geografia Física Aplicada - Território Brasileiro: Dinâmicas, Potencialidades e Vulnerabilidades, 2015. p. 969-975.

WOLLMANN, C. A.; SIMIONI, J. P. D. Variabilidade espacial dos atributos climáticos na Estação Ecológica do Taim (RS), sob domínio polar. Revista do Departamento de Geografia. São Paulo. Vol. 25, p. 56-76, 2013. 